\title{
LEAF-WATER RELATIONS OF A NATIVE AND AN INTRODUCED GRASS SPECIES IN THE MIXED-GRASS PRAIRIE UNDER CATTLE GRAZING
}

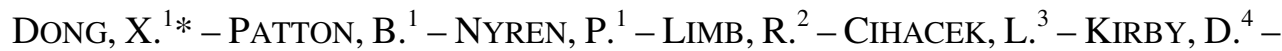 \\ DECKARD, E. ${ }^{5}$ \\ ${ }^{1}$ Institution North Dakota State University, Central Grasslands Research Extension Center, \\ Streeter, ND 58483 USA \\ ${ }^{2}$ North Dakota State University, Department of Animal and Range Science, Fargo, ND 58108 \\ USA;Present address: Oregon State University, Department of Rangeland Ecology \& \\ Management, La Grande, Oregon 97850, USA \\ ${ }^{3}$ North Dakota State University, Department of Soil Science, Fargo, ND 58108 USA \\ ${ }^{4}$ North Dakota State University, Department of Animal and Range Science, Fargo, ND 58108 \\ USA;Present address: North Dakota State University, School of Natural Resource Sciences, \\ Fargo, ND 58108 USA \\ ${ }^{5}$ North Dakota State University, Department of Plant Science, Fargo, ND 58108 USA \\ *Corresponding author \\ e-mail: xuejun.dong@ndsu.edu \\ (Received $8^{\text {th }}$ November 2011; accepted $2^{\text {nd }}$ December 2011)
}

\begin{abstract}
Both the native Pascopyrum smithii and introduced Poa pratensis are dominant plants in the mixed-grass prairie. Knowledge of leaf-water relations and water use strategies in these two grasses under animal grazing and drought is needed for understanding responses of the prairie to future climate change. We studied leaf-water relations traits of Pascopyrum and Poa by combined use of information from the pressure-volume analysis, leaf structural characteristics and leaf stomatal conductance as a function of leaf water status. Fieldwork was done in three grazed pastures and three exclosures in 2002 and 2003. With growing season drought, available soil water became lower in the grazed pastures than in the nongrazing exclosures. This had a more negative impact on leaf water status of the shallow-rooted Poa than the deep-rooted Pascopyrum. In both grasses, a significant decrease in leaf stomatal conductance occurred near the turgor loss water potentials of -2.42 MPa for Poa and -3.5 MPa for Pascopyrum, respectively. Both Poa and Pascopyrum responded to grazing with more negative osmotic potentials (and thus more concentrated cell solution) in months of peak growth. Specific leaf area and its two components, i.e., leaf density and thickness, had minimum responses to grazing for Pascopyrum, while in Poa, less dense leaves accompanied by a higher specific leaf area was observed, suggesting that long-term grazing encourages a higher potential growth rate but also a higher susceptibility to drought stress in Poa than in Pascopyrum.
\end{abstract}

Keywords: leaf density, leaf osmotic potential, Pascopyrum smithii, Poa pratensis, specific leaf area

\section{Introduction}

In the Great Plains of North America, widespread dispersal of introduced plants, such as Poa pratensis L. and Bromus inermis (Rydb.) A. Love, alter plant community structure (Murphy and Grant, 2005) and challenge grassland management (DeKeyser et al., 2010). On grasslands, one major task is to understand plant water-relations and water use strategies constrained by grazing and drought (Svejcar and Christiansen, 1987a; Wraith et al., 1987; Heitschmidt et al., 1999). However, even the question of 
whether animal grazing actually can alter plant water status on grasslands is still not fully answered. Although many studies had showed a positive effect of grazing on water status of the remaining plants (Archer and Detling, 1986; Svejcar and Christiansen, 1987a, 1987b; Day and Detling, 1994; Bremer et al., 2001), factors such as developmental stage of the same species, genetic differences between species (Mohammad et al., 1982; Frank, 1994), variations in rooting depths (Wraith et al., 1987; Fahnestock and Knapp, 1993; Jefferson and Cutforth, 2005), as well as grazing intensity (Fahnestock and Detling, 2000), all can influence the observed plant water status under field conditions. Under certain situations, conserved soil moisture due to the removal of green leaves by heavy grazing cannot compensate for the increased soil evaporation and/or run-off due to grazing induced bare-soil exposure (Patton and Nyren, 1998). This dictates the need for additional site- and context-specific study of leaf-water relations of grassland plants.

The specific strategies in leaf-water relations that plants employ to cope with varied biotic and abiotic stresses can be inferred (a) from the pressure-volume (PV) analysis (Turner, 1981); (b) from measuring specific leaf area (SLA) and its components: leaf density and leaf thickness (Witkowski and Lamont, 1991; Niinemets, 2001; Mojzes et al., 2003); and (c) from the relationship between leaf stomatal conductance $\left(g_{s}\right)$ and leaf water potential $(\psi)$ (Bittman and Simpson, 1989). While the PV traits for assaying leafwater relations is widely used (Monson and Smith, 1982; Sinclair and Venables, 1983; Schulte and Hinckley, 1985; Parker and Colombo, 1995; Dong and Zhang, 2001; Lenz et al., 2006), the use of SLA and its two components primarily for assaying leaf-water relations is relatively less emphasized (Maxwell and Redmann, 1978; Rascio et al., 1990; Krasser and Kalapos, 2000; Niinemets, 2001). As leaf density correlates tightly with leaf elastic modulus governing leaf turgidity response to dehydration across a broad range of plants (Niinemets, 2001), its value for indicating overall cell wall rigidity, a major component dictating leaf-water relations, is apparent. Actually, SLA itself carries information of plant water status (Garnier et al., 2001; Roderick, 2001). Furthermore, the fact that the other component of SLA (leaf thickness) scales well with light (Chabot and Chabot, 1977; Nobel and Hartsock, 1981; Witkowski and Lamont, 1991) and leaf "liquid content" (Roderick et al., 2000) provides a linkage from leaf water status to photosynthetic light capturing. These two ways of characterizing leafwater relations, namely, the PV-based and the leaf structure-based, can be used together to enable a better interpretation of the roles played by eco-physiological traits in siteand context-specific studies determining plant resource use (Smith and Knapp, 2001) and drought adaptations (Krasser and Kalapos, 2000).

We used both the PV-based and SLA-based traits to study leaf-water relations of a native grass Pascopyrum smithii and an introduced grass Poa pratensis in a mixed-grass prairie (Lura et al., 1988; Biondini et al., 1998; Patton and Nyren, 1998). Dominant in this mixed-grass prairie (Patton et al, 2007), Pascopyrum is excellent forage grass and fully adapted to grazing and drought (Coupland and Johnson, 1965). Poa, an introduced grass responding to high water/nutrient supply and frequent cutting (Jiang and Huang, 2001a), also dominates on mixed-prairies (Murphy and Grant, 2005; DeKeyser et al., 2010). The rooting depth of Pascopyrum may reach $2 \mathrm{~m}$ or deeper into soil profile (Weaver, 1926; Coupland and Johnson, 1965), while for Poa, roots may reach down to 40-45 cm (Gist and Smith, 1948; Peterson et al., 1979; Jiang and Huang, 2001b). These contrasts in rooting depth may depict differences in plants' access to soil moisture (Stewart et al., 2004), as well as in leaf-water relations traits (Krasser and 
Kalapos, 2000). On the other hand, grazing may not only reduce plant rooting depth (Mohammad et al., 1982; Wraith et al., 1987; Rogers et al., 2005), it also encourages the development of "less expensive" leaves (Niinemets, 2001) that are thinner, less dense, but potentially more prone to drought stress (Díaz et al., 2001; Cingolani et al., 2007; Rotundo and Aguiar, 2008). Moreover, leaf structural traits of grassland plants may also exhibit a seasonal variation (Mojzes et al., 2003). Finally, while leaf $g_{s}$ has been shown to decrease with the decrease of leaf $\psi$ (Jarvis, 1976; Bittman and Simpson, 1989), and the relationship was described to be either linear (Kim and Verma, 1991) or non-linear (Abril and Hanano, 1998), the lack of relevant data on Pascopyrum and Poa limits our ability to predict the leaf gas exchange characteristics of these two species under varied water supply on the prairie.

Based on above considerations, we asked the following research questions and used relevant field data and analysis to address them. (a) Is soil water conserved under grazing compared with non-grazing control in this mixed-grass prairie? (b) What are the intrinsic differences in leaf-water relations traits between Poa and Pascopyrum growing in the mixed-grass prairie? (c) How does cattle grazing influence the leaf-water relations traits of these two species and what are the potential impacts of these influences, if any, on the performance of Poa and Pascopyrum in a changed climate?

\section{Materials and methods}

\section{Site description}

The study site has a continental type climate with an average Jan. temperature of $17^{\circ} \mathrm{C}$ and Aug. temperature of $20^{\circ} \mathrm{C}$. Mean annual precipitation is $458 \mathrm{~mm}$ with about $70 \%$ occurring during May to Sep. Elevation is about $587 \mathrm{~m}$.

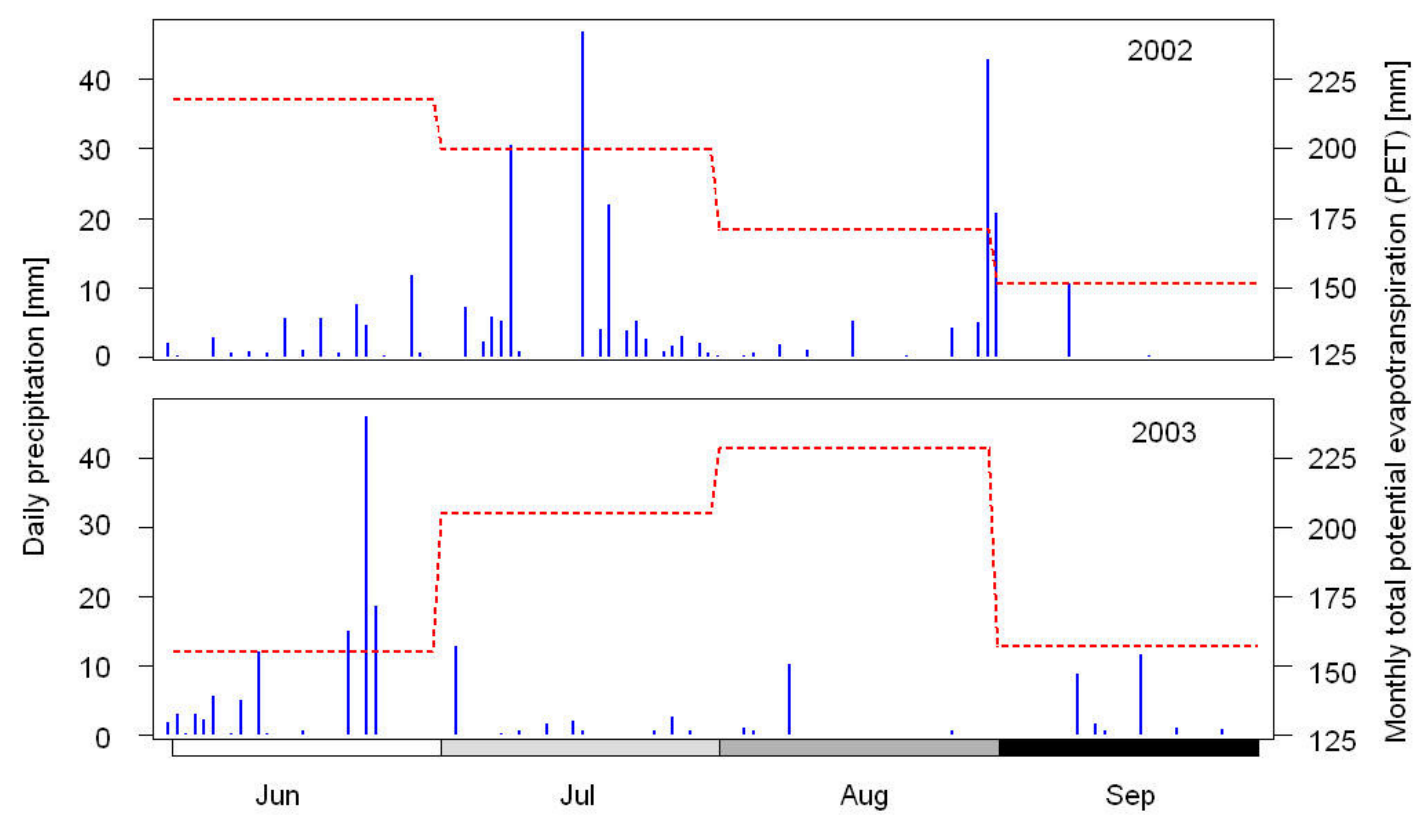

Figure 1. Daily precipitation (solid lines) and monthly total potential evapotranspiration (PET, dotted lines, from http://ndawn.ndsu.nodak.edu) at the Central Grasslands Research Extension Center (CGREC), Streeter, ND, from Jun. to Sep. in 2002 and 2003 
The vegetation is dominated by grasses, with forbs contributing $20 \%$ and shrubs $2 \%$ of the peak standing crop (Lura et al, 1988). The dominant grasses include Poa pratensis L., Bromus inermis Leyss. and Pascopyrum smithii (Rydb.) A. Love; dominant forbs include Aster ericoides L., Oligoneuron rigidum [L.] Small var. humile [Porter] Nesom, Artemisia ludoviciana Nutt., and Achillea millefolium L., and the dominant shrub is Symphoricarpos occidentalis Hook. Field measurements were conducted in 2002 and 2003 on 3 non-grazing exclosures, the size of which ranges from 1050 to $2020 \mathrm{~m}^{2}$, and 3 grazed pastures, each about 13 ha in size and stocked at 6.8 AUM (animal unit month) ha ${ }^{-1}$ since 1988 within a long-term grazing intensity study trial (Patton et al., 2007). An animal unit (AU) is defined as one mature $454 \mathrm{~kg}$ cow with calf or its equivalence based on an average forage consumption of $12 \mathrm{~kg}$ of dry matter per day. Cattle were removed from pastures when approximately $850 \mathrm{~kg} \mathrm{ha}^{-1}$ of forage remained at the end of the grazing season. Both growing seasons in 2002 and 2003 experienced drought with uneven distribution of precipitation (Fig. 1).

\section{Leaf water potential and soil water content}

Leaf $\psi$ of Pascopyrum and Poa was measured in the early morning (one hour after sunrise) using a pressure chamber (PMS Instrument Co. Model-1000, Corvallis, Oregon USA). The distance between pastures prevented us from measuring leaf $\psi$ from all the six pastures/exclosures that were used in SLA measurement (see below). Instead, we selected a representative exclosure and a grazed pasture for field sampling. The measurements were made 3-5 times from mid-Jun. to mid-Sep. with a replication of 6 leaves for each species-treatment combination. For each measurement period, we were not able to make the measurements at different locations within on one morning but within 3 adjacent mornings without rain interruption. Soil water content was measured once every two weeks from Jun. to Sep. using a neutron probe (Troxler 4300 Depth Moisture Gauge, Research Triangle Park, NC USA). One access tube was installed at a typical silty location (Patton et al. 2007) in each of the six pastures/exclosures. The data were converted into available water (cm of water) to the depths of $0-23 \mathrm{~cm}$ and $0-83 \mathrm{~cm}$ by subtracting soil water content at $-1.5 \mathrm{MPa}$ (permanent wilting point) from total soil water content for a particular soil depth. The purpose of choosing these two depth intervals is to roughly represent shallow and deep soil water reserves available to plants (Dong et al., 2010), although some roots may reach much deeper into the soil profile (Weaver, 1958; Coupland and Johnson, 1965).

\section{Leaf water potential and soil water content}

In 2002, leaf samples of Pascopyrum and Poa were collected in three grazed pastures and three exclosures. The samples were collected in four time periods, i.e., May 17-24, Jun. 17 to Jul. 8 (Jun-Jul), Aug. 1-17, and Sep. 24 to Oct. 2 (Sep) on non-rainy days. On each sampling day, leaves of the two species each were collected twice, i.e., ca. 1-2 hr. after sunrise and ca. 2-3 hr. after noon, each with 3 batches (one batch contained ca. 5060 leaves). By sampling twice a day, we hoped to obtain specific leaf area (SLA) measurements that roughly represented diurnal average values (Garnier et al., 2001). Once severed from the plant, leaves were sealed in plastic bags, stored in a chilled cooler and transported to the laboratory in ca. $20 \mathrm{~min}$. for further processing. Both senescent and immature leaves were avoided. In each of the locations ( 2 grazing levels 
$\times 3$ sites $=6$ locations), leaf samples were obtained randomly from within an area ca. 10-15m away from a permanent soil access tube for measuring soil water (see above).

Each batch of leaves was used to measure leaf volume, leaf area and leaf dry mass. Leaf volume was measured by displacement of water in a cylinder (precision $0.05 \mathrm{~cm}^{3}$ ). The relative error for the volume measurement for ca. $1 \mathrm{~g}$ leaves (fresh mass) was estimated to be ca. 5\%. To measure leaf area, leaves were laid flat (unfolding Poa leaves if necessary) on transparent contact paper. The image was scanned into the computer and total leaf area was calculated using image processing software SigmaScan Pro 5.0 (SPSS Inc. Chicago, IL USA). Then, leaves were removed from the contact paper and oven-dried to measure dry mass. Leaf density was calculated as leaf dry mass per unit leaf volume; leaf thickness was calculated by dividing leaf volume by leaf area, and specific leaf area (SLA) was calculated from leaf area divided by leaf dry mass.

\section{Leaf pressure-volume curves}

Due to the time-consuming nature of constructing leaf pressure-volume (PV) curves, only one grazed pasture and one exclosure were used to collect leaves of the two species (Pascopyrum and Poa) in 2003. The criteria for leaf selection were the same as that in the SLA measurement. Leaf samples from both locations were collected three times: Jun. 22 to Jul. 7 (Jun-Jul); Jul. 28 to Aug. 1 (Jul-Aug); and Sep. 6-8 (Sep). In the JunJul sampling, 30 leaves of each grass species were collected from each of the two locations. In the Jul-Aug sampling, 60 leaves of each of the two species were available to be sampled; in the Sep sampling, 60 leaves of only Pascopyrum were collected (Poa leaves were not available). The leaf samples were collected in the morning from $0900 \mathrm{~h}$ to $1130 \mathrm{~h}$ local time, placed in plastic bags, stored in a chilled cooler and promptly transferred to the laboratory for further processing. In each sampling day, leaves of only one plant species from a particular location (exclosure or grazed site) were collected. About 2/3 of the leaves were subjected to saturation treatment following the procedure of Garnier et al (2001). The remaining leaves were used directly for generating a portion (and usually the drier portion) of the PV curve, using the "composite" method of Parker and Colombo (1995), in which many leaves were used to construct a single PV curve. The water-saturated leaves were placed on a bench for different time durations, allowing water loss through transpiration, and paired water potential $(\psi)$ and water content measurements were made according to Turner (1981). Leaf $\psi$ was measured with a pressure chamber as described above and water content was obtained by measuring fresh and dry mass of leaves to the nearest ten thousandth of a gram. One composite PV curve (with 30 to 60 data points each) was generated for each treatment/species combination in each of the measurement periods (Jun-Jul, Jul-Aug or Sep).

\section{Leaf stomatal conductance in field conditions}

Leaf stomatal conductance $\left(g_{s}\right)$ and $\psi$ for both Pascopyrum and Poa were measured in the field. In 2002, $g_{s}$ was measured using a LI-COR 6200 Portable Photosynthesis System (LI-COR Inc., Lincoln, Nebraska USA) on six selected days (Jul. 3, Jul. 5, Aug. 27 and Sep. 4-6) in an exclosure and two grazed pastures. The days were mostly clear with the actual photosynthetically active radiation (PAR) ranging from 1030 to 1839 $\mu \mathrm{mol}$ photon $\mathrm{m}^{-2} \mathrm{~s}^{-1}$, air temperature from 28.9 to $39.6{ }^{\circ} \mathrm{C}$, and relative humidity from 25.6 to $64.1 \%$ for all the measurements recorded. The measurements were made once 
every two hours from about $1100 \mathrm{~h}$ to $1800 \mathrm{~h}$ local time with each measurement made on four different leaves. Meanwhile, leaf $\psi$ was measured using a pressure chamber (same as described above) on six leaves each day from about $1200 \mathrm{~h}$ to $1400 \mathrm{~h}$ local time, except in Sep. 4-6, the measurements were made once every two hours immediately following $g_{s}$ measurement. In 2003, $g_{s}$ was measured using a LI-COR 6400 Portable Photosynthesis System (LI-COR Inc., Lincoln, Nebraska USA) on 12 selected days (Jun. 16-19, Jul. 17, Jul. 21-23, Aug. 21-22 and Aug. 25-26) in an exclosure and two grazed pastures. The $g_{s}$ measurement was made once an hour, or once every two hours, from about $1100 \mathrm{~h}$ to $1800 \mathrm{~h}$ local time. Each measurement was made under a fixed PAR of $2000 \mu \mathrm{mol}$ photon $\mathrm{m}^{-2} \mathrm{~s}^{-1}$. Depending on ambient PAR that the leaves had been experiencing prior to the measurement, about 15-40 min was needed in order to let stomata fully acclimate to this high light condition. The leaf $\psi$ measurement was made on six leaves using a pressure chamber each day from about $1200 \mathrm{~h}$ to $1400 \mathrm{~h}$ local time.

\section{Statistical data analysis}

\section{Specific leaf area (SLA) in relation to grazing and season}

The averaged values of SLA, leaf thickness and leaf density for leaves collected from one pasture in a particular sampling period was considered as one sample. So, there were 3 replications for each grazing level in each sampling period $(n=3)$. In Sep. 2002, samples for Poa were available from only 3 of the 6 sampling locations. These data were excluded from the statistical analysis. So the data for Poa presented here cover the periods of May, Jun-Jul and Aug, while the data for Pascopyrum cover the periods of Jun-Jul, Aug, and Sep. The ANOVA procedure of the General Linear Model (GLM) was used for the data analysis with three leaf properties, namely, SLA, leaf density and leaf thickness, considered as dependent variables, and sampling time (month) and grazing intensity as fixed factors crossed with each other. The three dependent variables were checked for normality in distribution, and leaf thickness was transformed to its natural logarithm. Post hoc comparisons of specific combinations of treatments were performed using the Tukey method with the convention of $(\mathrm{P}<0.05)$ in MINITAB 13.39 (Minitab Inc, State College, PA, USA).

\section{Specific leaf area (SLA) correlated with leaf density and leaf thickness}

We conducted correlation analysis between SLA and its two components (leaf thickness and leaf density) by pooling the original measurements from different pastures/locations and different sampling periods within a common grazing $(n=54)$. The analysis was done using both the Pearson correlation procedure in MINITAB and permutation resampling according to Hesterberg et al. (2006). For the resampling analysis, the null hypothesis was: the observed correlation coefficient $(r)$ was purely due to spurious source and there was no causal mechanism between the two variables. The alternative hypothesis was: there existed a causal mechanism between the two variables because the observed correlation coefficient could not occur purely by chance. Using this program, we drew 2000 resamples from the measured original data (of SLA, leaf thickness and leaf density) and obtained the median of the simulated $r$ values for the null model $\left(r_{o}\right)$, the $95 \%$ confidence interval (C.I.) for the simulated $r$, as well as the $p$ - 
value that the observed $r$ occurred purely by chance. The computer simulations were conducted separately for Pascopyrum and Poa under different grazing treatments.

\section{Fitting the pressure-volume curves}

Because the regression analysis of the PV curves used relative water deficit $\left(R_{w d}\right)$ as the independent variable, measured water content data (leaf dry mass based) was converted to $R_{w d}$ by the formula $R_{w d}=\left(M_{s}-M_{f}\right) /\left(M_{s}-M_{d}\right)$, where $M_{s}$ is the saturated leaf mass, $M_{f}$ the fresh leaf mass and $M_{d}$ the oven-dried leaf mass. First, the whole data set was fitted using a single non-linear equation according to Sinclair and Venables (1983) and Schulte and Hinckley (1985):

$$
\psi=\psi_{\pi, \mathrm{s}}\left[-\mathrm{e}^{-\mathrm{aR}} \mathrm{wd}+\frac{\mathrm{x}}{\mathrm{x}-\mathrm{R}_{\mathrm{wd}}}\right]
$$

where $R_{w d}$ is the relative water deficit, $\psi_{\pi, s}$ is the osmotic potential at full turgor, $x$ the symplastic water fraction at full turgor and $a$ is a constant influencing the change of pressure potential. Parameter $x$ was not further analyzed because the estimated $x$ values by the "composite" PV method tended to be too high to be physiologically meaningful (Parker and Colombo, 1995).

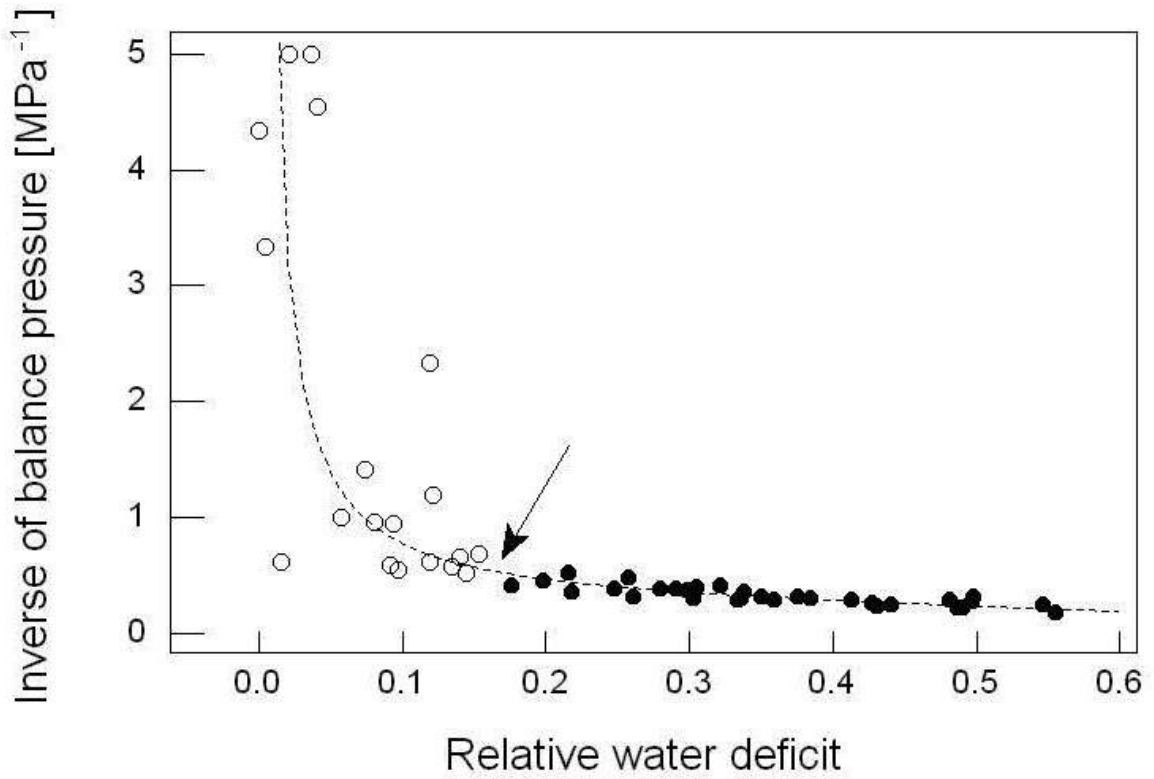

Figure 2. A sample pressure-volume curve for leaves of Pascopyrum smithii growing in an ungrazed exclosure, measured from Jul. 28 to Aug. 1, 2003. Each data point represents the measurement made on one leaf blade. First, the whole data set was fitted using a non-linear curve (dotted line). Then, by visual inspection, the data points belonging to the linear portion (solid circles) were located and fitted using a linear regression to obtain osmotic potential at full turgor (solid line). The waterpotentials at initial turgor loss point were estimated by systematically comparing the fitted linear and non-linear curves (see the main text)

By plotting the fitted Equation 1 as inverse of balance pressure $(1 / P)$ against $R_{w d}$ (Turner, 1981), the trend of the original data was described by a linear portion and a non-linear portion (Fig. 2). Using visual inspection, the transition point between the non-linear and the linear portions was located. Using data points from the linear portion, 
a linear regression of inverse of $P$ against $R_{w d}$ was obtained for each PV curve according to Sinclair and Venables (1983):

$$
1 / \mathrm{P}=-1 / \psi_{\pi, \mathrm{s}}+\left(1 / \psi_{\pi, \mathrm{s}} \mathrm{x}\right) \mathrm{R}_{\mathrm{wd}}
$$

where all symbols are the same as in Equation 1. The recipe of linear regression analysis from Zar (1984) was used to calculate the 95\% confidence intervals for the Yintercepts of the linear part of the PV curves (Fig. 2), which was then used to compute $\psi_{\pi, s}$. The osmotic potential at turgor loss point $\left(\psi_{t l p}\right)$ was estimated by comparing the nonlinear curve (Equation 1) and the linear curve (Equation 2). In particular, the whole range of the domain of Equations 1 and 3 (see Fig. 2) was sub-divided into 200 intervals. Then, starting from the lowest $R_{w d}$ end and moving toward the high $R_{w d}$ end, the two curves were compared systematically. When the relative difference first fell below a pre-set criteria of 5\%, the comparison stopped and the corresponding $\psi$ was regarded as $\psi_{t l p}$. Similar to $\psi_{\pi, s}$, the $95 \%$ C.I. for $\psi_{t l p}$ was also established according to Zar (1984); using the data points from the linear part of the PV curve (solid circles in Fig. 2). Finally, the standard error was obtained from the $95 \%$ C.I. and the number of data points.

\section{Leaf stomatal conductance in relation to leaf water potential}

Grazing's effect on $g_{s}$ was not compared because the measurements of $g_{s}$ for pastures of different grazing treatments were made on different days in both the 2002 and 2003 growing seasons. Instead, the overall trends of $g_{s}$ as a function of leaf $\psi$ were analyzed separately for Pascopyrum and Poa. To aid the interpretation of species-specific $g_{s}$ $\psi$ relationship, we also computed the overall distributions of the turgor loss points for the two species separately. For Poa, for example, we assumed that the estimated four means of the turgor loss points in Table 1 (for different grazing treatments across different sampling periods) were drawn from a common normal distribution of Poa's turgor loss point: $f(\psi)=\frac{1}{\sigma \sqrt{2 \pi}} e^{-(\psi-\bar{\psi})^{2} / 2 \sigma^{2}}$, where the average of $\psi, \bar{\psi}$, was estimated as $\bar{\psi}=\sum_{i=1}^{4} m_{i} / 4$, and the standard deviation $\sigma$ was estimated as $\sigma=\sqrt{18 \sum_{i=1}^{4} s_{i}{ }^{2} / 4}$. In the above, $m_{i}$ and $s_{i}$ are mean and standard error, respectively, for each treatment-sampling period combination for Poa in Table 1, and the factor 18 is the average data points used.

Table 1. A comparison of the leaf water potentials (MPa) at the turgor loss point for plants growing in an exclosure and in a grazed pasture, as determined from the pressure-volume curves. Leaf samples were collected three times in the growing season of 2003: Jun. 22 to Jul. 7 (Jun-Jul), Jul. 28 to Aug. 1 (Jul-Aug), and Sep. 6-8 (Sep). The data are means with standard errors and number of data points in parentheses. Within a row, different lowercase letters indicate the existence of statistically significant difference between grazing treatments $(p=0.05)$

\begin{tabular}{c|c|c|c}
\hline Species & Sampling period & Exclosure & Grazed \\
\hline Poa & Jun-Jul & $-1.98^{\mathrm{a}}(0.10,6)$ & $-3.19^{\mathrm{b}}(0.10,9)$ \\
& Jul-Aug & $-2.21^{\mathrm{a}}(0.05,38)$ & $-2.31^{\mathrm{a}}(0.17,16)$ \\
Pascopyrum & Jun-Jul & $-2.73^{\mathrm{b}}(0.06,8)$ & $-2.27^{\mathrm{a}}(0.11,21)$ \\
& Jul-Aug & $-2.73^{\mathrm{a}}(0.10,25)$ & $-4.39^{\mathrm{b}}(0.16,11)$ \\
& Sep & $-4.77^{\mathrm{a}}(0.21,15)$ & $-4.13^{\mathrm{a}}(0.17,16)$ \\
\hline
\end{tabular}




\section{Results}

\section{Leaf water potentials and available soil water}

In 2002, despite several heavy rains occurring in Jul. (total $143.7 \mathrm{~mm}$ ) and late Aug., the driest condition in soils for both the $0-23 \mathrm{~cm}$ and $0-83 \mathrm{~cm}$ depths occurred in mid- to late Jun. and mid-Aug. (Fig. 3E,G). Despite the drought, the early morning leaf $\psi$ of Pascopyrum maintained relatively stable, with values seldom dropping below $-3 \mathrm{MPa}$ (Fig. $3 C$ ). However, leaf $\psi$ differed between Poa plants growing in the exclosure and in the grazed pasture (Fig. 3A): leaf $\psi$ in the exclosure seldom dropped below $-2 \mathrm{MPa}$, but the values for Poa from the grazed pasture tended to be much lower, with the lowest value reaching -5.42 MPa on Aug. 24, 2002.

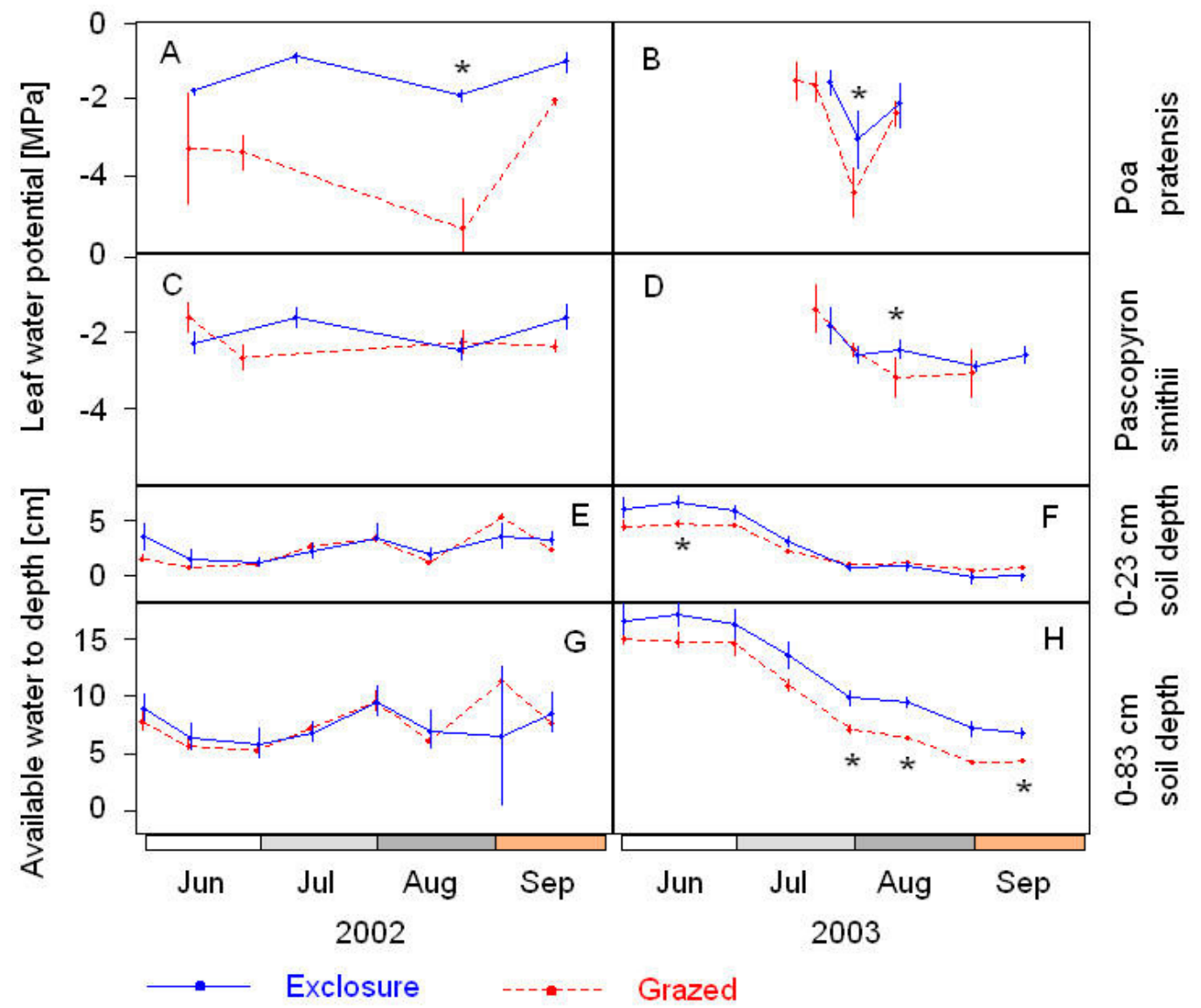

Figure 3. Leaf water potentials of Poa pratensis $(A, B)$ and Pascopyrum smithii $(C, D)$, as well as available soil water $(E-H)$ in 2002 and 2003. The data of available soil water are for depths of $0-23 \mathrm{~cm}(E, F)$ and $0-83 \mathrm{~cm}(G, H)$. Vertical bars are $95 \%$ confidence intervals for leaf water potentials $(n=5-6)$ and standard errors for available soil water $(n=3)$. Cases of significant difference between grazing treatments $(p<0.05)$ are indicated with stars (for leaf water potentials, only the data in Aug. are compared)

As shown in Fig. 3F, H, the available soil water in Jun., 2003 started with high values for both the $0-23 \mathrm{~cm}$ and $0-83 \mathrm{~cm}$ depths, largely due to the above-average precipitation in May (data not shown) and Jun. However, with sharply reduced rainfall and increased potential evapotranspiration in Jul. (Fig. 1), soil water in both depths decreased rapidly. By early to mid-Aug., available soil water in the $0-23 \mathrm{~cm}$ depth had 
decreased to minimum level for both the exclosure and the grazed pasture (Fig. $3 F$ ). Meanwhile, available soil water for the $0-83 \mathrm{~cm}$ depth dropped by $45 \%$ and $57 \%$ from the mid-Jun. values of $17.2 \mathrm{~cm}$ and $14.9 \mathrm{~cm}$ for the exclosure and grazed pasture, respectively. The larger percentage decline in available water in the grazed pasture resulted in lower available soil water in the grazed pasture than in the non-grazing exclosure in early to mid-Aug. (Fig. 3H). For Poa, the drought in early Aug. of 2003 resulted in a decreased leaf $\psi$ for plants growing both in the exclosure and grazed pasture, with the average value in grazed pasture (-4.45 MPa) being significantly lower than that in the exclosure (-3.05 MPa), as measured on Aug. 1-2, 2003. For Pascopyrum, however, the overall decrease in leaf $\psi$ was less in extent than in Poa on Aug. 1-2, and there was no significant difference associated with grazing. Following a $10.25 \mathrm{~mm}$ rainfall on Aug. 9, 2003, the Pascopyrum's leaf $\psi$ in the exclosure was slightly improved as measured on Aug. 12 (Fig. 3D), while the leaf $\psi$ for Pascopyrum plants growing in the grazed pasture kept decreasing, resulting in a significantly lower $\psi$ value $($ avg $=-4.45 \mathrm{MPa})$ than the average value in the exclosure $(-3.05 \mathrm{MPa})$. On the other hand, we can see that leaf $\psi$ of Poa plants from both the exclosure and the grazed pasture improved following the Aug. 9 rain event (Fig. 3B).

\section{Effects of grazing and season on specific leaf area and its two components}

For pooled data, there was no significant difference in leaf density between the two species $\left(t\right.$-test Avg. $=0.31 \mathrm{~g} \mathrm{~cm}^{-3}$, df $\left.=34, p=0.98\right)$, while leaf thickness was significantly higher in Pascopyrum (avg. $=0.027 \mathrm{~cm})$ than in Poa $($ avg. $=0.02 \mathrm{~cm})(p<$ 0.001). As shown in Figs. 4 and 5, SLA was significantly lower in Pascopyrum (avg. = $\left.128.4 \mathrm{~cm}^{2} \mathrm{~g}^{-1}\right)$ than in Poa $\left(\right.$ avg. $\left.=173.5 \mathrm{~cm}^{2} \mathrm{~g}^{-1}\right)(p<0.001)$.

\section{Poa pratensis}

Both month and grazing had significant effects on SLA of Poa $(p=0.032$ and $p=$ 0.047, respectively). For the month factor, SLA did not change significantly from May to Jun-Jul $(p=0.41)$, but increased significantly from Jun-Jul to Aug. $(p=0.025)$. Overall, SLA was significantly higher under grazed than in exclosure $(p=0.048)$. However, this significance was mainly due to the marginally bigger contrasts in SLA between grazing treatments in Aug. ( $p=0.094$, see Fig. 4A). For leaf density of Poa, the factor of month had highly significant overall effect through the 2002 growing season $(p<0.0005)$, with a significant increase from May to Jun-Jul ( $p=0.0007$, Fig. $4 B)$. The overall effect of grazing on leaf density was not significant $(p=0.128)$. For leaf thickness (Fig. 4C), the effect of month was again highly significant $(p<0.0005)$, with the average leaf thickness decreased from $0.023 \mathrm{~cm}$ in May to $0.019 \mathrm{~cm}$ in Jun-Jul ( $p=0.002)$, and further decreased to $0.016 \mathrm{~cm}$ in Aug. $(p=0.018)$. Neither grazing $(p=$ $0.43)$ nor the interaction of grazing and month $(p=0.61)$ had a significant effect. 


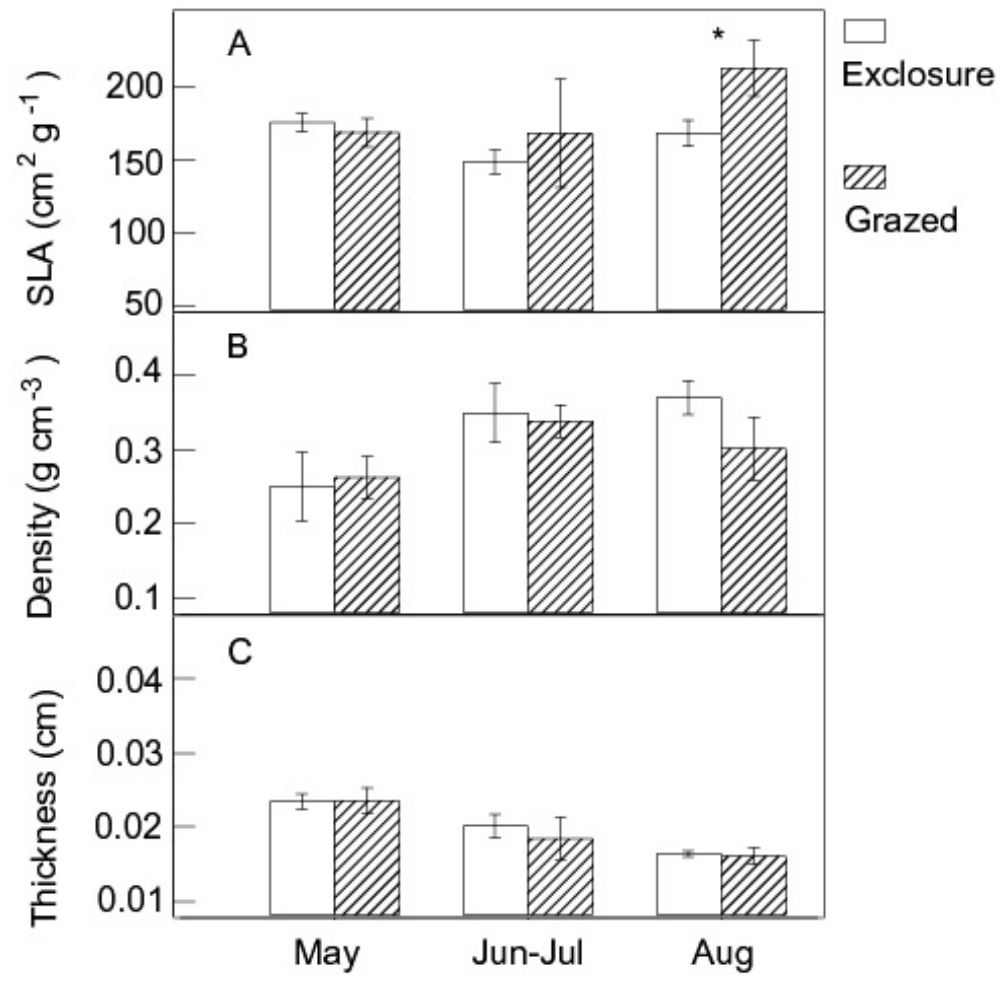

Figure 4. A comparison of three leaf properties (specific leaf area, leaf density and thickness) of Poa pratensis growing in ungrazed exclosures (white) and in grazed pastures (right slant) in different sampling periods from May to Aug., 2002. The data shown are the averaged values and standard deviations $(n=3)$. The symbol "*” indicates marginal significant difference at $p<0.1$

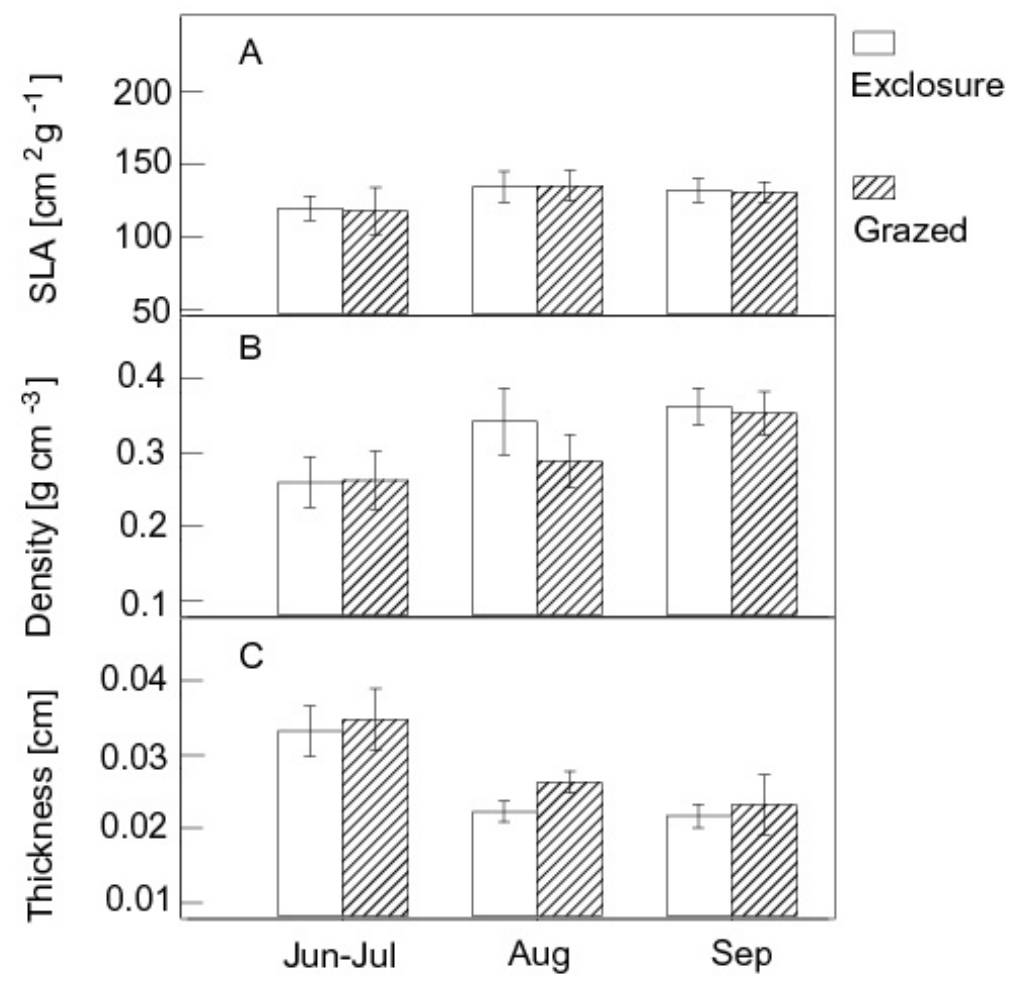

Figure 5. Same as in Figure 4, but with Pascopyrum smithii

APPLIED ECOLOGY AND ENVIRONMENTAL RESEARCH 9(4): 311-331. http://www.ecology.uni-corvinus.hu • ISSN 15891623 (Print) • ISSN 17850037 (Online) (C) 2011, ALÖKI Kft., Budapest, Hungary 


\section{Pascopyrum smithii}

Month had a significant overall effect $(p=0.05)$ on SLA of Pascopyrum, which resulted mainly from the significant increase in SLA from Jun-Jul to Aug. ( $p=0.053$, see Fig. 5A). However, neither grazing $(p=0.86)$ nor the interaction of grazing and month $(p=0.97)$ had a significant effect, suggesting that in different sampling periods SLA had similar trends for different grazing treatments. Similar to SLA, leaf density of Pascopyrum was only significantly influenced by month $(p=0.002)$, but not by grazing $(p=0.25)$ or the interaction of grazing and month $(p=0.38$, see Fig. 5B). Again similar to SLA, the significant overall month effect on leaf density resulted mainly from the significant increase in leaf density from Jun-Jul to Aug. ( $p=0.05$, see Fig. 5B). Leaf thickness of Pascopyrum was significantly influenced by month $(p<0.0005)$.
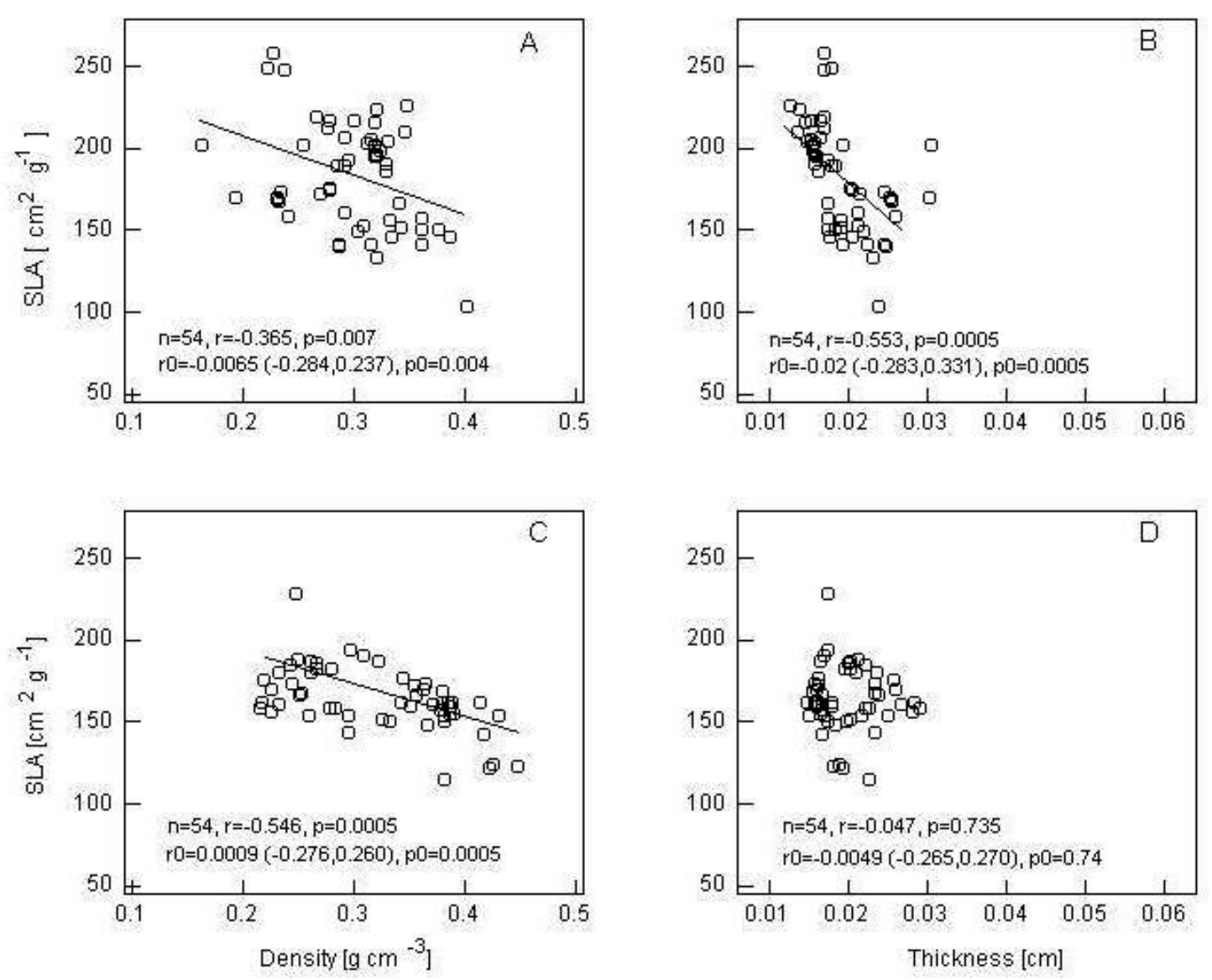

Figure 6. Correlations between specific leaf area (SLA) and leaf dry matter density and between SLA and leaf thickness for Poa pratensis plants growing in grazed pastures $(A, B)$ and in ungrazed exclosures $(C, D)$. Each data point represents the measurement made on a composite sample of 12-20 leaves. Shown in the figures are sample size ( $n$ ), the Pearson correlation coefficients ( $r$ ), and associated probabilities $(p)$. Also indicated are results from permutation resampling of the null model, including the medium values ( $r 0)$, the $95 \%$ confidence intervals of correlation coefficients of the null models, as well as the associated probabilities $(\mathrm{p} 0)$ 


\section{Correlations of specific leaf area with leaf density and leaf thickness}

In Poa, the correlations of SLA with leaf density and leaf thickness show different patterns with different grazing treatments (Fig. O). While under grazing both leaf density and leaf thickness were negatively correlated with SLA (Fig. 6A,B), in nongrazed exclosures the significant correlation existed between SLA and leaf density, but not between SLA and leaf thickness (Fig. 6C,D). In Pascopyrum, however, a similar pattern in the correlation between SLA and its two components was observed for different grazing treatments: SLA was significantly correlated with leaf thickness but not with leaf density for both grazing (Fig. 7A,B) and exclosures (Fig. 7C,D). In all cases, the results from standard Pearson correlation test were confirmed and reinforced by the results from permutation resampling.
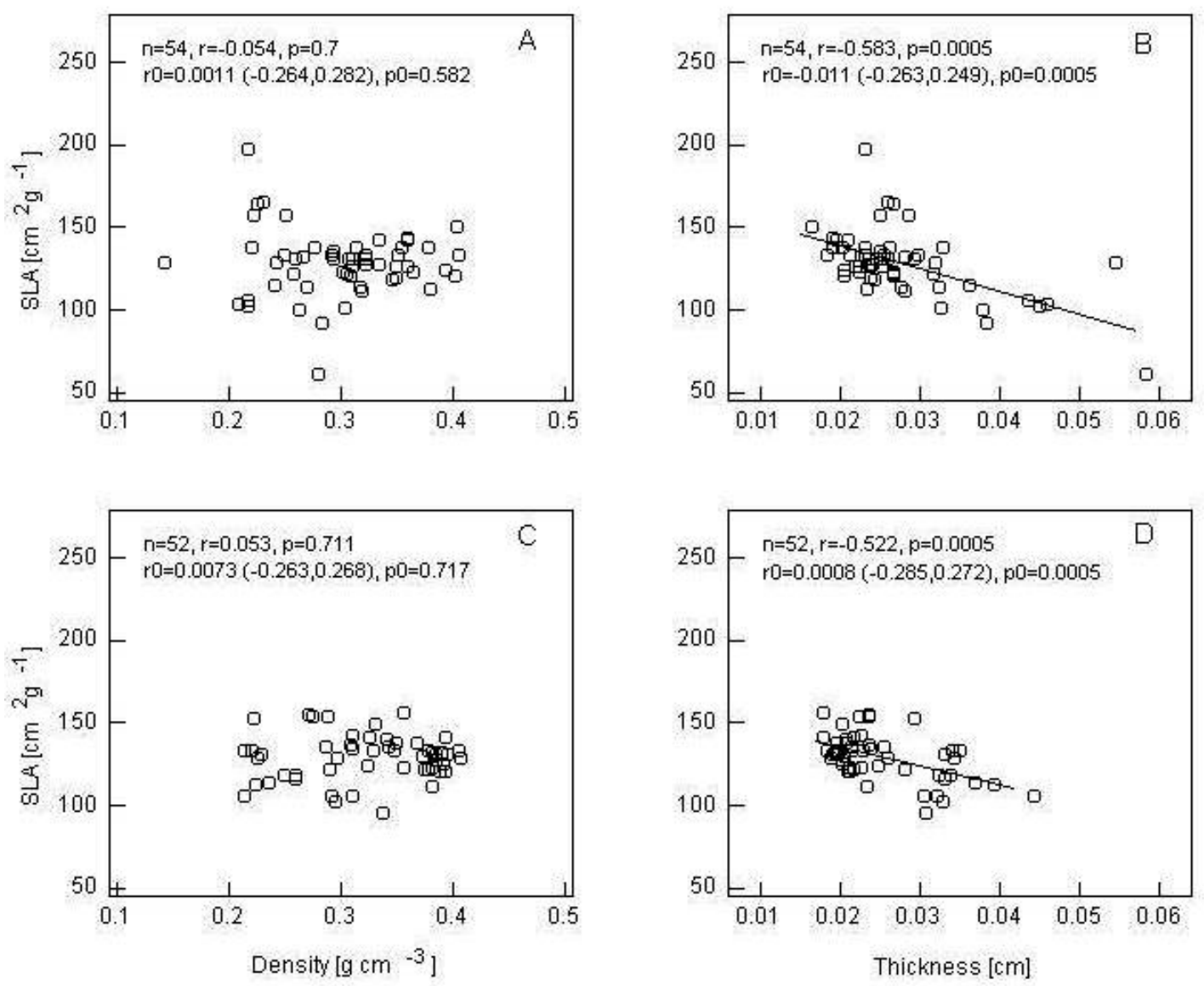

Figure 7. Same as in Figure 6 except that the data are for Pascopyrum smithii

\section{Leaf-water relations traits from pressure-volume analysis}

In the Jun-Jul sampling period, the osmotic potential at full turgor $\left(\psi_{\pi, s}\right)$ for Poa plants growing in the grazed pasture was significantly lower than those in the exclosure. In Jul-Aug, however, there was no significant difference between grazing treatments, with an average $\psi_{\pi, s}$ value of $-1.56 \mathrm{MPa}$. For Pascopyrum, plants growing in the grazed pasture had significantly lower $\psi_{\pi, s}$ values than in exclosure for both the Jun-Jul and JulAug sampling periods, with the average value of $\psi_{\pi, s}$ for grazed reaching as low as -3.07 
MPa in Jul-Aug. Similar to Poa, the effect of grazing disappeared for the last sampling period (Sep. for Pascopyrum). Overall, the average value of $\psi_{\pi, s}$ for Pascopyrum (-2.37 $\mathrm{MPa})$ was marginally lower than that of Poa $(-1.53 \mathrm{MPa})(p=0.052)$. The effect of grazing on leaf water potentials at turgor loss point $\left(\psi_{t l p}\right)$ was not as clear-cut as in $\psi_{\pi, s}$. As shown in Table 1, $\psi_{t l p}$ was significantly lower under grazing than in exclosure for Poa in Jun-Jul and for Pascopyrum in Jul-Aug. However, for Pascopyrum in the Jun-Jul sampling period, the $\psi_{t l p}$ value in exclosure was significantly lower than that in grazed. Similar to $\psi_{\pi, s}$, the effect of grazing on $\psi_{t l p}$ was not observed in the last sampling periods of Poa (in Jul-Aug) and Pascopyrum (in Sep.).

\section{Leaf stomatal conductance in relation to leaf water potential}

While the $g_{s}-\psi$ relationship for Pascopyrum was fitted using only one regression line, the relationship for Poa leaves was fitted using two regression lines with different slopes delineating a bimodal behavior of the $g_{s}-\psi$ relationship in less negative and more negative ranges of $\psi$ in both years. As shown in Fig. 9A, in 2002, the $g_{s}-\psi$ relationship for Poa for less negative range of leaf $\psi$ (with open, or unfolded leaves) was fitted using regression line $g_{s}=1.17+0.329 \psi\left(R^{2}=0.55, p=0.014\right)$, while the relationship for more negative range of leaf $\psi$, where the Poa leaves were folded, was described by the regression line $g_{s}=0.489+0.054 \psi\left(R^{2}=0.79, p=0.303\right)$. Although the only three data points for the folded Poa leaves (each was an average of data from 4-8 leaves) are not enough for establishing a statistically significant regression line, the trend of data suggests a bimodal behavior in the $g_{s}-\psi$ relationship in Poa. The intersection point of the two lines (for Poa) has a coordinate with $\psi=-2.48 \mathrm{MPa}$ (solid arrow in Fig. 9A) and $g_{s}=0.356 \mathrm{~mol} \mathrm{H} \mathrm{O} \mathrm{m}^{-2} \mathrm{~s}^{-1}$. The $g_{s}-\psi$ relationship for Pascopyrum was fitted by a single regression line of $g_{s}=1.74+0.378 \psi\left(R^{2}=0.62, p=0.001\right)$, which intersects the line for folded Poa leaves at $\psi=-3.86 \mathrm{MPa}$ (dashed arrow in Fig. 9A) and $g_{s}=0.281$ mol $\mathrm{H}_{2} \mathrm{O} \mathrm{m}^{-2} \mathrm{~s}^{-1}$. Interestingly, the solid arrow and dashed arrow fall within the $95 \%$ confidence intervals of the distribution of $\psi_{t l p}$ for Poa and Pascopyrum, respectively. The means ( $\mu=-2.42 \mathrm{MPa}$ and $\mu=-3.5 \mathrm{MPa}$ for Poa and Pascopyrum, respectively) and the standard deviations used for drawing the distribution (assumed normal) of $\psi_{t l p}$ were obtained from data in Table 1. Although the "turning point" for Pascopyrum is only hypothetical, the above correspondence between the "turning points" of the $g_{s^{-}}$ $\psi$ relationship and the distribution of $\psi_{t l p}$ provides evidence for a mutual support of the validity of both our measured stomatal behavior data and the PV-based parameter of leaf turgor maintenance.

The same pattern of the $g_{s}-\psi$ relationship and the "match" between stomatal behavior and $\psi_{t l p}$ in Poa and Pascopyrum were also seen in the 2003 growing season (Fig. 9B), though the maximum $g_{s}$ for both species tended lower in 2003 than in 2002. Also, the slopes of the regression lines of the $g_{s}-\psi$ relationship for both species were lower than the respective values in 2002, with unfolded and folded Poa leaves fitted to the regression lines of $g_{s}=0.356+0.065 \psi\left(R^{2}=0.14, p=0.37\right)$ and $g_{s}=0.241+0.025 \psi$ (determined using two points), respectively, and Pascopyrum leaves fitted to the regression line of $g_{s}=0.774+0.166 \psi\left(R^{2}=0.44, p=0.01\right)$. The $\psi$ values at the intersecting points for Poa and Pascopyrum are $-2.76 \mathrm{MPa}$ (solid arrow in Fig. 9B) and -3.77 MPa (dashed arrow in Fig. 9B), respectively. Note that, in Pascopyrum, the $\psi$ values at the "turning points" of the $g_{s}-\psi$ relationship in 2002 and 2003 were quite similar, while in Poa, the $\psi$ value for the "turning point" in 2003 was more negative than that in 2002. 


\section{Discussion}

Although the total precipitation received at our field site from Jun. to Sep. 2002 $(280.3 \mathrm{~mm})$ was higher than the 52-year long-term average (which was $264.6 \mathrm{~mm}$ ), Poa plants growing in the grazed pasture experienced lower leaf $\psi$ than the average of its turgor loss point starting early Jul. 2002 (Fig. 3A and Fig. 9). This occurred despite the observed similar available soil water in both the $0-23 \mathrm{~cm}$ and $0-83 \mathrm{~cm}$ soil depths in 2002. The severe drought of 2003 (with total precipitation from Jun. to Sep. of 170.3 $\mathrm{mm})$ may have caused leaf $\psi$ values to be close to or much below the $\psi_{t l p}$ values of Pascopyrum and Poa, respectively, especially in mid-Aug. Our data (Fig. 3) suggest that growing season drought can exacerbate the soil and plant water status, with more detrimental impacts on shallow-rooted plants such as Poa. This is in agreement with a study from the same field site by Patton and Nyren (1998), but disagrees with several studies from other parts of the Great Plains of North America (Archer and Detling, 1986; Svejcar and Christiansen, 1987a, 1987b; Day and Detling, 1994; Bremer et al., 2001).

The results in Fig. 9 indicate that significant decrease in leaf $g_{s}$ of Poa occurred near the turgor loss water potential $\left(\psi_{t l p}\right)$, which demarcates a higher $\psi$ range, where leaf gas exchange responds sensitively to the change in $\psi$, and lower $\psi$ range, where $g_{s}$ stagnates at low or minimum values and leaf cells may experience partial to irreversible damage due to severe dehydration. Moreover, the average $\psi_{t l p}$ of $-2.42 \mathrm{MPa}$ in Poa roughly corresponds to the leaf-folding $\psi$ of -2.3 to $-2.5 \mathrm{MPa}$ in late Aug. 2002 at our study site (X. Dong, field observation). This is comparable with the leaf-rolling $\psi$ of Agropyron cristatum of -2.6 MPa in early Jul. in the mixed-grass prairie as observed by Bittman and Simpson (1989), who also established that the narrow threshold of leaf-rolling $\psi$ in Agropyron cristatum occurred roughly $0.1 \mathrm{MPa}$ lower than the measured leaf $\psi_{t l p}$. In our study, no leaf-rolling or -folding was observed for Pascopyrum, and field measured leaf $\psi$ of this grass was seldom lower than the $95 \%$ confidence interval of the distribution of $\psi_{t l p}$ (Fig. 9). However, leaf-rolling in Pascopyrum was observed for the highly dehydrated leaves during the construction of the PV curves (X. Dong, personal observation). Thus, despite the drought in 2002 and 2003 growing seasons, Pascopyrum appeared to maintain its $\psi$ from excessive decreasing, perhaps due to its deep-rooted habit in the mixed-prairie (Coupland and Johnson, 1965). Nevertheless, the fact that the intersection point between the single regression line of the $g_{s}-\psi$ relationship in Pascopyrum and that of Poa (Fig. 9) falls within the 95\% confidence interval of Pascopyrum's $\psi_{t l p}$ distribution suggests that the $g_{s} \psi$ relationship for whole range of leaf $\psi$ in Pascopyrum might, though hypothetically, be described as shown in Fig. 9. 


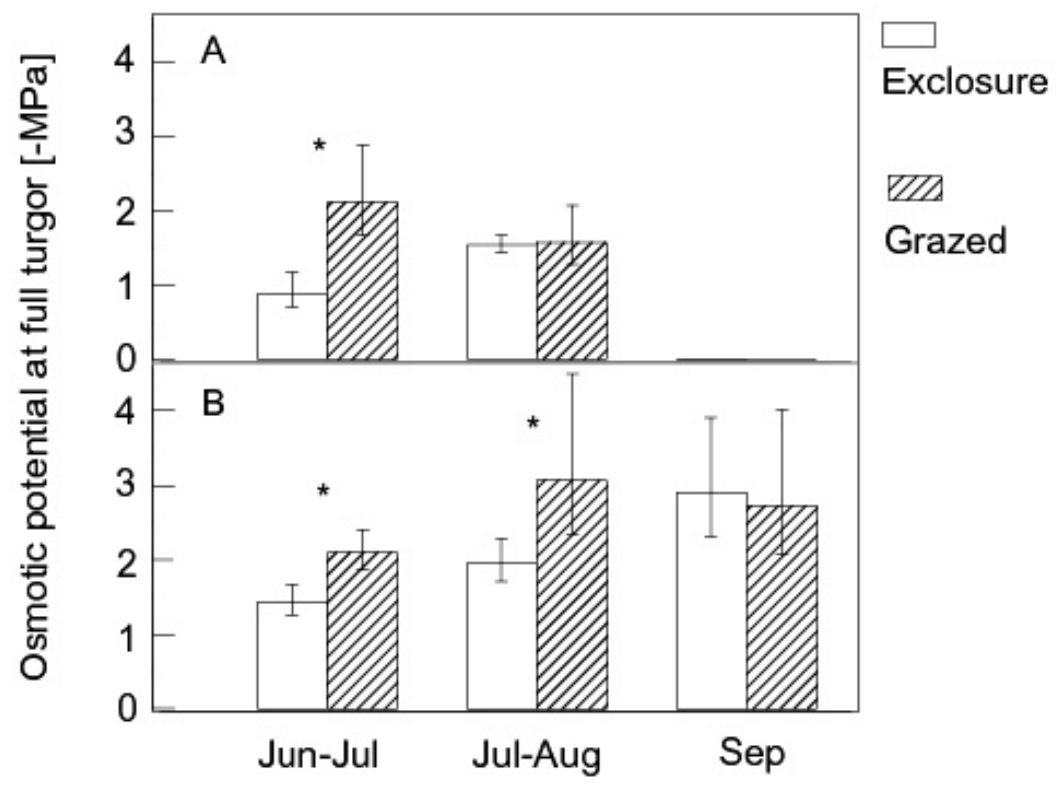

Figure 8. Osmotic potentials of leaves of Poa pratensis (A) and Pascopyrum smithii (B) as a function of grazing and season. The error bars represent the $95 \%$ confidence intervals for the means. The symbol $*$ indicates significant difference at $p=0.05$

How does cattle grazing influence the leaf-water relations traits of Poa and Pascopyrum? Our data on both leaf structural (Figs. 4-5 and Figs. 6-7) and PV (Table 1 and Fig. 8) parameters suggest that, although both Poa and Pascopyrum responded to grazing with more negative osmotic potentials (and thus more concentrated cell solution) in months of peak growth, specific leaf area and its two components, i.e., leaf density and thickness, had minimum responses to grazing for Pascopyrum, while in $P o a$, a higher specific leaf area accompanied by a marginally lower leaf density was observed in grazed pastures compared with ungrazed exclosures, suggesting that longterm grazing encourages a higher potential growth rate but also a higher susceptibility to drought stress in Poa more than in Pascopyrum.

The consistent decrease in $\psi_{\pi, s}$ of both grasses in Jun-Jul and Aug. in association with grazing may be considered primarily as a physiological response to the severe summer drought in 2003 (Fig. 3B,D,F,H), although it might to same extent be linked with increased $g_{s}$ and photosynthetic rate due to grazing (Svejcar and Christiansen, 1987b), especially in the less drought affected Pascopyrum (see Fig. 3D). In Pascopyrum, the more negative values in both $\psi_{\pi, s}\left(\right.$ Fig. 8) and $\psi_{t l p}$ (Table 1 and Fig. 9) than Poa suggests the greater osmotically effectiveness of the leaf solutes in Pascopyrum, which is in line with the conclusion of Frank (1994) that ".stress response mechanisms that enhance proline and abscisic acid (accumulations) may be more operative in western (wheatgrass) (Pascopyrum) than crested (wheatgrass) (Agropyron desertorum)". 


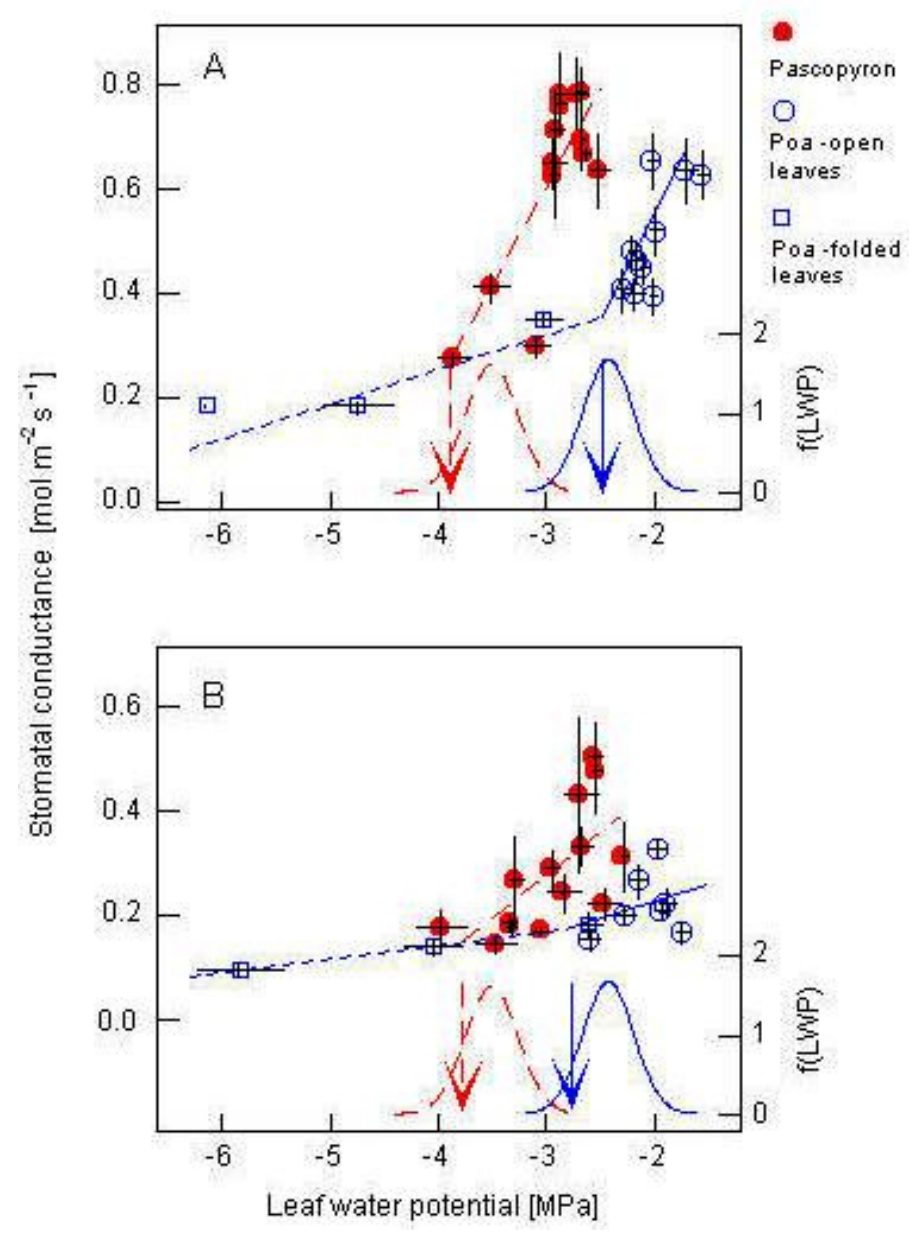

Figure 9. The observed bimodal relationship between stomatal conductance $\left(g_{s}\right)$ and leaf water potential ( $\psi$ ) of Poa pratensis leaves (open circles and squares) as measured under field conditions in 2002 (A) and 2003 (B). The mode of rapid change of $g_{s}$ as a function of $\psi$ is shown as open circles and fitted with a solid lines; the mode of slow change of $g_{s}$ is shown as open squares and fitted with dotted lines. The $\psi$ values for the junctions (solid arrows) fall within the 95\% limits of the normal distribution ( $f(L W P)$ ) with mean and standard deviation derived from data of the initial turgor loss point for Poa in Table 1. Like data of Pascopyrum smithii (solid circles) was fitted with single linear regressions (dashed lines) and the $\psi$ values for the hypothetical junction points (dashed arrows) also match the corresponding normal curve for data of the turgor loss point for Pascopyrum in Table 1. Each data point represents the averaged measurements on 3-12 leaves and the error bars are for standard errors

Regarding SLA and its components (leaf density and leaf thickness), although there is a general agreement between our results (Figs. 4-5) and literature data regarding effects of season (Mojzes et al., 2003) and animal grazing (Cingolani et al., 2007), our data suggest a contrast in leaf structural responses to grazing between Poa and Pascopyrum. In Pascopyrum, the responses of leaf density and leaf thickness to grazing largely canceled the effects of each other, resulting in an almost unchanged SLA, which departed from the predicted general responses according to Cingolani et al. (2007). This unresponsiveness in Pascopyrum's leaf structure is further confirmed by the similarity 
between grazing treatments in the pooled correlations of SLA and its two components (Fig. 7). Thus we conclude that leaf-water relations of Pascopyrum respond to grazing through significantly lowering osmotic potentials, instead of increasing leaf density or cell wall rigidity.

In Poa, the increased drought tolerance due to decreased $\psi_{\pi, s}$ (Fig. 8) and $\psi_{t l p}$ (Table 1) associated with grazing was countered by the tendency of increased SLA in the JunJul and Aug. sampling periods (Fig. 4A), which were brought about by the tendency of concomitant decrease in leaf density (Fig. 4B) and leaf thickness (Fig. 4C), although only in Aug. there were marginally significant differences in SLA and leaf density between plants growing in the grazed pastures and those in the exclosures. Even though there were only three replicates $(n=3)$ in our statistics, the information "content" of each measurement was high, because each measurement of SLA was the average of six composite samples each of which contained 50-60 leaves. Thus we consider the marginal significant results of Fig. 4 to be ecologically important. In addition, the responsiveness of $P o a$ 's leaf structure to grazing is further confirmed by the contrast in correlations of SLA and its two components between the exclosures and grazed pastures (Fig. 6). The higher SLA for Poa plants in the grazed pastures, as compared with the exclosures, may be considered as a grazing mitigation strategy in that less leaf mass per unit of leaf area is removed in each defoliation event (Rotundo and Aguiar, 2008). However, a higher SLA and lower leaf density suggests a weakened capacity for water conservation through the reduction of leaf pressure potentials (Krasser and Kalapos, 2000; Niinemets, 2001), as about $80 \%$ of leaf water potential reduction of naturally transpiring leaves occurs between the full turgor and turgor loss point (Cheung et al., 1975; Maxwell and Redmann, 1978). On the other hand, a higher SLA associated with grazing also implies a higher relative growth rate (Rotundo and Aguiar, 2008) and a competitive advantage under good water supply (Martin and Chamber, 2001). This is in line with the conclusion that long-term overgrazing did not significantly weakened Poa's vigor (in terms of above-ground plant biomass percentage) compared with moderate grazing, during the relatively wet spell of the past two decades from the same site as the current study (Patton et al., 2007). As a result, we conclude that, although leaf-water relations of Poa respond to grazing through significantly lowering osmotic potentials, increased SLA and leaf density associated with grazing render both an advantage of increased relative growth rate under good water availability and a disadvantage of susceptibility to water loss under drought stress.

One of the major goals of grassland management is to maintain and enhance the growth of native species, such as Pascopyrum, while keeping exotic species, such as $P o a$, in check (DeKeyser et al., 2010). Based on our analysis, we suggest that grazing in drought years may help to weaken $P o a$ 's vigor and tip the relative competitiveness of the two species in favor of Pascopyrum. Thus, our data provide an enhanced understanding linking leaf-water relations traits of two dominant plant species with plant resource use and stress resistance on the mixed-grass prairie under cattle grazing.

Acknowledgements. This work was part of North Dakota Agricultural Experiment Station projects ND6146, ND6147 and ND6149. We appreciate the support of staff members of Central Grasslands Research Extension Center, North Dakota State University. 


\section{REFERENCES}

[1] Abril, M., Hanano, R. (1998): Ecophysiological responses of three evergreen woody mediterranean species to water stress. - ACTA Oecologia 19: 377-387.

[2] Archer, S., Detling, J.K. (1986): Evaluation of potential herbivore mediation of plant water status in a North American mixed-grass prairie. - Oikos 47: 287-291.

[3] Biondini, M.E., Patton, B.D., Nyren, P.E. (1998): Grazing intensity and ecosystem processes in a northern mixed-grass prairie, U.S.A. - Ecological Applications 8: 469-479.

[4] Bittman, S., Simpson, G.M. (1989): Drought effect on leaf conductance and leaf rolling in forage grasses. - Crop Science 29: 338-34.

[5] Bremer, D.J., Auen, L.M., Ham, J.M., Owensby, C.E. (2001): Evapotranspiration in a prairie ecosystem: Effects of grazing by cattle. - Agronomy Journal 93: 338-348.

[6] Chabot, B.F., Chabot, J.F. (1977): Effects of light and temperature on leaf anatomy and photosynthesis in Fragaria vesca. - Oecologia 26: 363-377.

[7] Cheung, Y.N.S., Tyree, M.T., Dainty, J. (1975): Water relations parameters on single leaves obtained in a pressure bomb and some ecological interpretations. - Canadian Journal of Botany 53: 1342-1346.

[8] Cingolani, A.M., Cabido, M., Gurvich, D.E., Renison, D., Díaz, S. (2007): Filtering processes in the assembly of plant communities: Are species presence and abundance driven by the same traits? - Journal of Vegetation Science 18: 911-920.

[9] Coupland, R.T., Johnson, R.E. (1965): Rooting characteristics of native grassland species in Saskatchewan. - Journal of Ecology 53: 475-507.

[10] Day, T.A., Detling, J.K. (1994): Water relations of Agropyron smithii and Bouteloua gracilis and community evapotranspiration following long-term grazing by prairie dogs. - American Midland Naturalist 132: 381-392.

[11] DeKeyser, S., Meehan, M., Sedivec, K., Lura, C. (2010): Potential management alternatives for invaded rangelands in the Northern Great Plains. - Rangelands 32: 26-31.

[12] Díaz, S., Noy-Meir, I., Cabido, M. (2001): Can grazing response of herbaceous plants be predicted from simple vegetative traits? - Journal of Applied Ecology 38: 497-508.

[13] Dong, X., Zhang, X. (2001): Some observations of the adaptations of sandy shrubs to the arid environment in the Mu Us Sandland: Leaf water relations and anatomic features. Journal of Arid Environments 48: 41-48.

[14] Dong, X., Patton, B.D., Nyren, A.C., Nyren, P.E., Prunty, L.D. (2010): Quantifying root water extraction by rangeland plants through soil water modeling. - Plant and Soil 335: 181-198.

[15] Fahnestock, J.T., Detling, J.K. (2000): Morphological and physiological responses of perennial grasses to long-term grazing in the Pryor Mountains, Montana. - American Midland Naturalist 143: 312-320.

[16] Fahnestock, J.T., Knapp, A.K. (1993): Water relations and growth of tallgrass prairie forbs in response to selective grass herbivory by bison. - International Journal of Plant Science 154: 432-440.

[17] Frank, A.B. (1994): Physiological comparisons of crested wheatgrass and western wheatgrass to water. - Journal of Range Management 47: 460-466.

[18] Garnier, E., Shipley, B., Roumet, C., Laurent, G. (2001): A standardized protocol for the determination of specific leaf area and leaf dry matter content. - Functional Ecology 15: 68-695.

[19] Gist, G.R., Smith, R.M. (1948): Root development of several common forage grasses to a depth of eighteen inches. - Agronomy Journal 40: 1036-1042.

[20] Heitschmidt, R.K., Haferkamp, M.R., Karl, M.G., Hild, A.L. (1999): Interactive effects of drought and grazing on Northern Great Plains rangelands. - Journal of Range Management 52: 440-446. 
[21] Hesterberg, T., Moore, D.S., Monaghan, S., Clipson, A., Epstein, R. (2006): Bootstrap methods and permutation tests. - In: Moore, D.S., McCabe, G.P. (eds) Introduction to the Practice of Statistics, W. H. Freeman, New York, Chapter 14.

[22] Jarvis, P.G. (1976): The interpretation of the variations in leaf water potential and stomatal conductance found in canopies in the field. - Philosophical Transactions of the Royal Society of London [Biology] 273: 593-610.

[23] Jefferson, P.G., Cutforth, H.W. (2005): Comparative forage yield, water use, and water efficiency of alfalfa, crested wheatgrass and spring wheat in a semiarid climate in southern Saskatchewan. - Canadian Journal of Plant Science 85: 877-888.

[24] Jiang, Y., Huang, B. (2001a): Effects of calcium on antioxidant activities and water relations associated with heat tolerance in two cool-season grasses. - Journal of Experimental Botany 52: 341-349.

[25] Jiang, Y., Huang, B. (2001b). Osmotic adjustment and root growth associated with drought preconditioning-enhanced heat tolerance in Kentucky bluegrass. - Crop Science 41: 1168-1173.

[26] Kim, J., Verma, S.B. (1991): Modeling canopy stomatal conductance in a temperate grassland ecosystem. - Agricultural and Forest Meteorology 55: 149-166.

[27] Krasser, D., Kalapos, T. (2000): Leaf water relations for 23 angiosperm species from steppe grasslands and associated habitats in Hungary. - Community Ecology 1: 123-131.

[28] Lenz, T.I., Wright, I.J., Westoby, M. (2006): Interrelations among pressure-volume curve traits across species and water availability gradients. - Physiologia Plantar. 127: 423-433.

[29] Lura, C.L., Barker, W.T., Nyren, P.E. (1988): Range plant communities of the Central Grasslands Research Station in South Central North Dakota. - Prairie Naturalist 20: 177192.

[30] Martin, D.W., Chamber, J.C. (2001): Effects of water table, clipping, and species interactions on Carex nebrascensis and Poa pratensis in riparian meadows. - Wetlands 21: 422-430.

[31] Maxwell, J.O., Redmann, R.E. (1978): Leaf water potential, component potentials and relative water content in a xeric grass, Agropyron dasystachyum (Hook.) Scribn. Oecologia 35: 277-284.

[32] Mohammad, N., Dwyer, D.D., Busby, F.E. (1982): Responses of crested wheatgrass and Russian wildrye to water stress and defoliation. - Journal of Range Management 35: 227230.

[33] Mojzes, A., Kalapos, T., Virágh, K. (2003): Plasticity of leaf and shoot morphology and leaf photochemistry for Brachypodium pinnatum (L.) Beauv. growing in contrasting microenvironments in a semiarid loess forest-steppe vegetation mosaic. - Flora 198: 304320.

[34] Monson, R.K., Smith, S.D. (1982): Seasonal water potential components of Sonoran Desert plants. - Ecology 63: 113-123.

[35] Murphy, R.K., Grant, T.A. (2005): Land management history and floristics in mixedgrass prairie, North Dakota, USA. - Natural Areas Journal 25: 351-358.

[36] Niinemets, U. (2001). Global-scale climatic controls of leaf dry mass per area, density, and thickness in trees and shrubs. - Ecology 82: 453-469.

[37] Nobel, P.S. (1999): Physicochemical and Environmental Plant Physiology. $-2^{\text {nd }}$ edn. Academic Press, San Diego, California, USA.

[38] Nobel, P.S., Hartsock, T.L. (1981): Development of leaf thickness for Plectranthus parviflorus-influence of photosynthetically active radiation. - Physiologia Plantarum 51: 163-166.

[39] Parker, W.C., Colombo, S.J. (1995): A critical re-examination of pressure-volume analysis of conifer shoots: Comparison of three procedures for generating PV curves on shoots of Pinus resinosa Ait. seedlings. - Journal of Experimental Botany 46: 1701-1709.

[40] Patton, B.D., Nyren, P.E. (1998): The effect of grazing intensity on soil water and rangeland productivity in south-central North Dakota. - In: Potts, D.F. (ed) Proceedings 
of the American Water Resources Association Special Conference, Rangeland Management and Water Resources, American Water Resources Association, Herndon VA, TPS-98-1, pp 219-228

[41] Patton, B.D., Dong, X., Nyren, P.E., Nyren, A. (2007): Effects of grazing intensity, precipitation, and temperature on forage production. - Rangeland Ecology and Management 60: 656-665.

[42] Peterson, L.A., Newman, R.C., Smith, D. (1979): Rooting depth of Kentucky bluegrass sod as measured by N absorption. - Agronomy Journal 71: 490-492.

[43] Rascio, A., Cedola, M.C., Topani, M., Flagella, Z., Wittmer, G. (1990): Leaf morphology and water status changes in Triticum durum under water stress. - Physiologia Plantarum 78: 462-467.

[44] Roderick, M.L. (2001): On the use of thermodynamic methods to describe water relations in plants and soil. - Australian Journal of Plant Physiology 28: 729-742.

[45] Roderick, M.L., Berry, S.L., Noble, I.R. (2000): A framework for understanding the relationship between environment and vegetation based on the surface area to volume ratio of leaves. - Functional Ecology 14: 423-437.

[46] Rogers, W.M., Kirby, D.R., Nyren, P.E., Patton, B.D., Dekeyser, E.S. (2005): Grazing intensity effects on Northern Plains mixed-grass prairie. - Prairie Naturalist 37: 73-83.

[47] Rotundo, J.L., Aguiar, M.R. (2008): Herbivory resistance traits in populations of Poa ligularis subjected to historically different sheep grazing pressure in Patagonia. - Plant Ecology 194: 121-133.

[48] Schulte, P.J., Hinckley, T.M. (1985): A comparison of pressure-volume curve data analysis techniques. - Journal of Experimental Botany 36: 1590-1602.

[49] Sinclair, R., Venables, W.N. (1983): An alternative method for analyzing pressurevolume curves produced with the pressure chamber. - Plant, Cell and Environment 6: 211-217.

[50] Smith, M.D., Knapp, A.K. (2001): Physiological and morphological traits of exotic, invasive exotic, and native plant species in tallgrass prairie. - International Journal of Plant Science 162:785-792.

[51] Stewart, J.R., Kjelgren, R., Johnson, P.G., Kuhns, M.R. (2004): Soil-water-use characteristics of precision-irrigated buffalograss and Kentucky bluegrass. - Applied Turfgrass Science. doi:10.1094/ATS-2004-1118-01-RS.

[52] Svejcar, T., Christiansen, S. (1987a): Grazing effects on water relations of Caucasian bluestem. - Journal of Range Management 40: 15-18.

[53] Svejcar, T., Christiansen, S. (1987b): The influence of grazing pressure on rooting dynamics of Caucasian bluestem. - Journal of Range Management 40: 224-227.

[54] Turner, N.C. (1981): Techniques and experimental approaches for the measurement of plant water status. - Plant and Soil 58: 339-366.

[55] Weaver, J.E. (1926): Root Development of Field Crops. - McGraw-Hill Book Company, Inc., New York

[56] Weaver, J.E. (1958): Classification of root systems of forbs of grassland and a consideration of their significance. - Ecology 39: 394-401.

[57] Witkowski, E.T.F., Lamont, B.B. (1991): Leaf specific mass confounds leaf density and thickness. - Oecologia 88: 486-493.

[58] Wraith, J.M., Johnson, D.A., Hanks, R.J., Sisson, D.V. (1987): Soil and plant water relations in a crested wheatgrass pasture: Response to spring grazing by cattle. Oecologia 73: 573-578.

[59] Zar, J.H. (1984): Biostatistical Analysis. $-2^{\text {nd }}$ edn. Prentice Hall, Englewood Cliffs, New Jersey. 